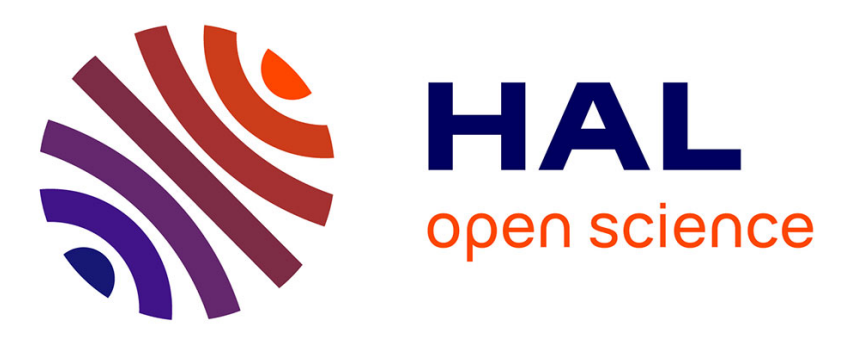

\title{
Multifunctional polymer composites reinforced by carbon nanotubes-Alumina hybrids with urchin-like structure
}

Delong He, Benhui Fan, Hang Zhao, Minhao Yang, Hui Wang, Jintao Bai, Wenyao Li, Xiying Zhou, Jinbo Bai

\section{To cite this version:}

Delong He, Benhui Fan, Hang Zhao, Minhao Yang, Hui Wang, et al.. Multifunctional polymer composites reinforced by carbon nanotubes-Alumina hybrids with urchin-like structure. Materials Today Communications, 2017, 11, pp.94-102. 10.1016/j.mtcomm.2017.03.001 . hal-01842497

\section{HAL Id: hal-01842497 https://hal.science/hal-01842497}

Submitted on 18 Apr 2020

HAL is a multi-disciplinary open access archive for the deposit and dissemination of scientific research documents, whether they are published or not. The documents may come from teaching and research institutions in France or abroad, or from public or private research centers.
L'archive ouverte pluridisciplinaire HAL, est destinée au dépôt et à la diffusion de documents scientifiques de niveau recherche, publiés ou non, émanant des établissements d'enseignement et de recherche français ou étrangers, des laboratoires publics ou privés. 
Multifunctional polymer composites reinforced by carbon nanotubes - alumina hybrids with urchin-like structure

Delong $H E^{l}$, Benhui $F A N^{l}$, Hang ZHAO ${ }^{l}$, Minhao YANG ${ }^{1}$, Hui $\mathrm{WANG}^{2}$, Jintao $\mathrm{BAI}^{2}$, Wenyao $\mathrm{Li}^{3}$, Xiying Zhou ${ }^{3}$, Jinbo BAI ${ }^{1,2 *}$

${ }^{[1]}$ Laboratoire Mécanique des Sols, Structures et Matériaux, CNRS UMR 8579, Ecole CentraleSupelec, Université Paris Saclay, Grande Voie des Vignes, 92290,

Chatenay-Malabry, France

${ }^{[2]}$ State Key Lab Incubation Base of Photoelectric Technology and Functional Materials, International Collaborative Center on Photoelectric Technology and Nano Functional Materials, Northwest University, Xi'an 710069, PR China

${ }^{[3]}$ School of Materials Engineering, Shanghai University of Engineering Science, 333 Longteng Road, 201620, China

${ }^{*}$ Corresponding author. E-mail address: jinbo.bai@ centralesupelec.fr (Jinbo Bai) 


\section{ABSTRACT}

Polymer composites with enhanced mechanical and functional properties are highly desired to develop light-weight function-integrated structures and devices. In this study, one kind of urchin-like hybrids was synthesized by in-situ growing CNTs on alumina microspheres $\left(\mu \mathrm{Al}_{2} \mathrm{O}_{3}\right)$, and their reinforcing effects to epoxy were investigated in detail. It was found that as compared to pure epoxy the CNTs- $\mu \mathrm{Al}_{2} \mathrm{O}_{3}$ hybrids/epoxy composites possess highly improved electrical, dielectric, thermal and mechanical properties, achieving an enhancement as high as 5 orders of magnitude in the AC conductivity, $92 \%$ and $56 \%$ in the thermal diffusivity and thermal conductivity, respectively, and $26 \%$ in the Young's modulus, when CNT mass fraction used was $2 \%$. Detailed analyses and various microstructural characterizations were also conducted in order to understand the multiscale reinforcement effects. The significant enhancements observed are mainly due to the urchin-like structure and improved CNT dispersion in the epoxy matrix.

Keywords: Carbon nanotube, Hybrid structure, Epoxy Composite 


\section{Introduction}

Nowadays polymer matrix-based composites, both thermosetting and thermoplastic, are extensively used in the fields of automotive, electronic packaging, new energy and construction, due to their low weight, high strength, high corrosion resistance, etc.[1, 2] Carbon nanotube (CNT) is one-dimensional nanostructure which have large surface area, high aspect ratio and extraordinary properties. And CNT-reinforced polymer composites are expected to have excellent mechanical and functional properties. $[3,4]$ Despite great efforts have been made from both academy and industry in past decades, the CNT composite properties are still much lower than the expected values.[5, 6] Two greatest stumbling blocks are the difficulty of homogeneous dispersion and the lack of control over the alignment of CNTs in polymer matrix. [7]

A number of methods have been developed to improve CNT dispersion in polymer matrix. Surface functionalization is one of the commonly used approaches whose principle is to attach chemical groups or molecules on CNT sidewall or ends using a chemical, physical or electrochemical way. $[8,9]$ The covalent functionalization is generally achieved by strong acidic or basic oxidation, halogenation, hydrogenation, cycloaddition, radical addition, plasma treatment, etc.[3, 8, 10, 11]. This unavoidably generates $\pi$ conjugation disruption, sidewall defects and shortening of nanotubes, and significantly impacts the composite mechanical properties and more profoundly their thermal and electrical properties. The non-covalent ways such as polymer wrapping[12, 13] and surfactants[14], based on van der Waals forces or $\pi-\pi$ stacking, are still limited due to the low thermal stability and weak mechanical performance of 
surfactants, compatibility, etc. Thus, a compromise between good dispersion and property deterioration is generally made for the available CNTs-contained composites.

Some studies have also been made to develop hybrid polymer composites reinforced by the mixture of microparticles and CNTs functionalized or as-produced. It is well known that microparticles-reinforced polymer composites are one of the most widely used reinforcing fillers of polymers used in the fields of paints, adhesives, dielectric layers, thermal conductive layers, etc. The microparticles include silica, alumina, silicon carbide, etc. [15] Yet a high mass fraction is commonly required to obtain an observable functional property improvement, which in turn greatly increases the composite density and makes the polymer very fragile. Thus, the partial replacement of micrometric particulates by CNTs may generate improved performance while reducing composite mass. Indeed, a number of multiscale polymer composites have been reported with different mixture systems consisting of carbon nanomaterials and inorganic fillers, such as MWCNT/clay [16-18], CNT/Graphene nanoplatelets [19, 20], CNT/BN[21], CNT/BaTiO 3 [22] and others[23]. Additionally, the mixtures have also been widely used as fillers for ceramic [24] and metal matrix-based composites [25]. The improved properties have been reported, which may partially attribute to increased dispersion of CNTs thanks to the existence of microparticles.

The hybrid structures consisting of CNTs strongly grafting on microparticles are expected to take good advantage of nano and micro synergistic reinforcements.[26, 27] 
The organized hybrid structures favor the control over CNT alignment in the composites. The hybrid structures have been reported to be successfully synthesized by in-situ growing CNTs on various micrometer materials, such as ceramic particles $\left(\mathrm{Al}_{2} \mathrm{O}_{3}, \mathrm{SiC}, \mathrm{BaTiO}_{3}, \mathrm{TiO}_{2}\right.$, etc.), graphene nanoplatelets (GNPs), and fibers (carbon, alumina, glass, etc.).[20, 28-32] Also, some studies show that the hybrids-reinforced nanocomposites have the improved mechanical and multifunctional properties, compared to a random mixture of CNTs and microparticles.[20, 33] It was well known that CNT growth and self-organization on the microparticles depend greatly on the substrate crystallization structure and morphologies, as well as CVD conditions used.[28, 31, 34] In most cases reported, the CNTs bundles (agglomerated) have been found, especially for long CNTs.[29, 35], which may generate structural defects in composites. Therefore, it is highly desired to have one kind of hybrid structure with well-dispersed but aligned CNTs in order to explore to a great extent their hybrid reinforcing role in mechanical and functional properties.

In this communication, we presented one kind of urchin-like hybrid structures with CNTs individually and radially distributed and grafted on $\mu \mathrm{Al}_{2} \mathrm{O}_{3}$, which is produced by a CVD method. The epoxy-based composites containing the hybrids were prepared with as-produced CNTs- $\mu \mathrm{Al}_{2} \mathrm{O}_{3}$. A significant improvement on the overall composite properties was achieved by incorporating urchin-like hybrids in epoxy matrix with relatively low CNTs loadings.

\section{Experimental}

2.1 In-situ CVD synthesis of urchin-like CNTs- $\mu \mathrm{Al}_{2} \mathrm{O}_{3}$ hybrids 
The synthesis of the CNTs- $\mu \mathrm{Al}_{2} \mathrm{O}_{3}$ hybrids was carried out by CVD in a quartz tube which was heated by an electrical resistance furnace $\left(\right.$ CARBOLITE $\left.^{\circledR}\right)$, as reported in reference [28]. Briefly, spherical $\mu \mathrm{Al}_{2} \mathrm{O}_{3}$ particles of $1-10 \mu \mathrm{m}$ in diameter, purchased from Performance Ceramic Company (Peninsula, OH, USA), were served as substrates which were homogeneously spread over a quartz plate $(30 \mathrm{~mm}$ in width $\times 500 \mathrm{~mm}$ in length). The quartz plate with the microparticles was put inside the quartz tube, and heated in the presence of a gas mixture of argon and hydrogen. Herein, the gas flow rates, argon $0.8 \mathrm{~L} \mathrm{~min}^{-1}$ and hydrogen $0.2 \mathrm{~L} \mathrm{~min}^{-1}$, were precisely controlled by a set of electronic mass flow meters (Bronkhorst ${ }^{\circledR}$, France). After heating about $30 \mathrm{~min}$ at the given temperature $800{ }^{\circ} \mathrm{C}$, a xylene (ACS, 98.5\%, Alfa Aesar) solution dissolved with $0.05 \mathrm{~g} \mathrm{ml}^{-1}$ ferrocene (ACS, 99\% Powder, Alfa Aesar) was injected at a speed of $12 \mathrm{ml} \mathrm{h}^{-1}$ into the reactor by a syringe injector in form of spray. The sprayed solution was carried into the reaction zone by the carrier gases with a total flow rate of $1 \mathrm{~L} \min ^{-1}$. Herein, the ferrocene was served as catalyst precursor. The solution injection time was $15 \mathrm{~min}$. After, the furnace was cooled down to room temperature under argon protective atmosphere $\left(1 \mathrm{~L} \mathrm{~min}^{-1}\right)$. The CNTs weight ratio in the as-synthesized urchin-like hybrids was about $20 \mathrm{wt} . \%$ according to thermogravimetric analysis (TGA) results.

2.2 Composite preparation 
Table 1.Varied mass fractions of the urchin-like $\mathrm{CNTs}-\mu \mathrm{Al}_{2} \mathrm{O}_{3}$ hybrids ( $w t_{\mathrm{CNTs}-\mu \mathrm{Al2O}}$ ) in the epoxy matrix composites, as well the ones of CNTs ( $\left.w t_{\mathrm{CNTs}}\right)$ and alumina microparticles $\left(w t_{\mu \mathrm{Al} 2 \mathrm{O} 3}\right)$, and the volume fraction of CNTs $\left(f_{\mathrm{CNTs}}\right)$.

\begin{tabular}{|c|c|c|c|c|}
\hline Sample & $\begin{array}{l}w t_{\mathrm{CNTs}-\mu \mathrm{Al} 2 \mathrm{O3}} \\
(\mathrm{wt} . \%)\end{array}$ & $\begin{array}{l}w t_{\mathrm{CNTs}} \\
(\mathrm{wt} . \%)\end{array}$ & $\begin{array}{l}w t_{\mu \mathrm{Al} 2 \mathrm{O} 3} \\
(\mathrm{wt} . \%)\end{array}$ & $\begin{array}{l}f_{\text {CNTs }} \\
(\text { vol. \%) }\end{array}$ \\
\hline Baseline-Pure epoxy & 0 & 0 & 0 & 0 \\
\hline Hybrid/Epoxy1 & 0.5 & 0.1 & 0.4 & 0.057 \\
\hline Hybrid/Epoxy 2 & 1.5 & 0.3 & 1.2 & 0.17 \\
\hline Hybrid/Epoxy 3 & 2.5 & 0.5 & 2 & 0.29 \\
\hline Hybrid/Epoxy 4 & 5 & 1 & 4 & 0.59 \\
\hline Hybrid/Epoxy 5 & 10 & 2 & 8 & 1.22 \\
\hline
\end{tabular}

The polymer matrix used in this study was epoxy resin (1080S, Resoltech Ltd., France) with curing agent (1084, Resoltech Ltd.). Firstly, the as-synthesized urchin-like CNTs- $\mu \mathrm{Al}_{2} \mathrm{O}_{3}$ hybrids were manually mixed slightly with epoxy resin at varied mass fractions as shown in Table 1. Then, the mixtures were further dispersed using a three-roll mill (EXAKT 80, Germany), following the following preparation protocol: $50 \mu \mathrm{m}$ for the gap between the rollers, $20 \mathrm{rpm}$ for the roller rotation speed, and 20 min for the dispersion time. After, the curing agent was added to the collected suspension at mass ratio of $1 / 3$ to the epoxy resin, and then manually mixed to obtain a homogeneous suspension. Then, the resulting mixture was firstly degassed for 30 min at room temperature in a vacuum oven, and then poured into an aluminum mold with dumbbell-shape and square, which was then fasten with 4 screw bolts. The composites were obtained by cured at $60{ }^{\circ} \mathrm{C}$ for $15 \mathrm{~h}$. Dumbbell-shape samples with 1 
$\mathrm{mm}$ in thickness, $50 \mathrm{~mm}$ in length and $4 \mathrm{~mm}$ in gage width were obtained and edge-polished for tensile testing according to ASTM D638. The samples with dimension about $10 \mathrm{~mm} \times 10 \mathrm{~mm} \times 1 \mathrm{~mm}$ were achieved for dielectric property, ac conductivity and thermal conductivity measurements.

\subsection{Characterizations}

\subsubsection{Thermogravimetric analysis (TGA)}

TGA of the CNTs- $\mu \mathrm{Al}_{2} \mathrm{O}_{3}$ hybrids was carried out using a thermal analyser (NETZSCH STA 449 F3), under a mixed atmosphere of oxygen and nitrogen with a flow rate of 20: $20 \mathrm{ml} \mathrm{min}^{-1}$, respectively. The analysed temperature range was from room temperature to $700^{\circ} \mathrm{C}$ with a heating rate of $10^{\circ} \mathrm{C} \mathrm{min}^{-1}$.

\subsubsection{Microstructure characterization}

The CNTs- $\mu \mathrm{Al}_{2} \mathrm{O}_{3}$ hybrids structures and the composite sections were characterised using a scanning electron microscope (SEM, LEO 1530 Gemini). Herein, the composite samples with different hybrid weight fractions were fractured in liquid nitrogen in order to keep their original matrix states, and the fractured surfaces were coated by a thin layer of gold to increase the samples' surface conductivity.

\subsubsection{Electrical and dielectric properties}

The AC conductivity and dielectric properties including dielectric permittivity $\left(\varepsilon^{\prime}\right)$ and loss tangent (tan $\delta)$ of the composites were measured using an impedance/gain-phase analyzer (Solatron 1260) with the frequency range from $10^{2}$ to 
$10^{7} \mathrm{~Hz}$ at 1 Volt at room temperature. The sample size used was $10 \mathrm{~mm} \times 10 \mathrm{~mm}$, and their double faces were coated with silver conductive paint before measurement.

According to the impedance magnitude $\left(Z^{*}\right)$ and impedance phase $(\theta)$ measured, the following parameters can be calculated:

$$
\begin{aligned}
& Z^{\prime}=|Z| \cos (\theta), \quad Z^{\prime \prime}=|Z| \sin (\theta) \\
& \varepsilon^{\prime}=\frac{1}{C_{0} \omega} \frac{-Z^{\prime \prime}}{Z^{\prime 2}+Z^{\prime 2}}, \quad \varepsilon^{\prime \prime}=\frac{1}{C_{0} \omega} \frac{Z^{\prime}}{Z^{\prime 2}+Z^{\prime 2}}, C_{0}=\varepsilon_{0} \frac{s}{d}, \omega=2 \pi f \\
& \sigma^{\prime}=\omega \varepsilon_{0} \varepsilon^{\prime \prime}, \sigma^{\prime \prime}=\omega \varepsilon_{0} \varepsilon^{\prime},
\end{aligned}
$$

$\operatorname{Tan} \delta=\varepsilon^{\prime \prime} / \varepsilon^{\prime}$

where, $Z^{\prime}$ and $Z^{\prime \prime}$ are real and imaginary part of the impedance, respectively, $\varepsilon^{\prime}$ and $\varepsilon^{\prime \prime}$ are effective dielectric permittivity and dielectric loss, respectively, $\varepsilon_{0}$ is the vacuum dielectric permittivity, $\mathrm{S}$ and $\mathrm{d}$ are the area and thickness of the sample, respectively, $\sigma^{\prime}$ and $\sigma^{\prime \prime}$ are real and imaginary part of AC conductivity, respectively, and $\tan \delta$ is loss tangent.

\subsubsection{Thermal conductivity}

The room temperature thermal diffusivity $(\alpha)$ and conductivity $(\lambda)$ of the composites were measured by using nanoflash method (NETZSCH LFA 447). The sample size was $10 \mathrm{~mm} \times 10 \mathrm{~mm} \times 1 \mathrm{~mm}$. Epoxy samples were coated with graphite before the measurement. Then, the composite thermal conductivity was determined according to the following equation:

$$
\lambda=\rho \cdot C_{\mathrm{p}} \cdot \alpha
$$

where $\rho$ is the composite density, and $\mathrm{C}_{\mathrm{p}}$ is the composite specific heat which can be obtained during the measurement simultaneously. 


\subsubsection{Mechanical properties}

The tensile tests of the dumbbell-shaped composite samples were carried out with a machine (Instron 5544 with a $2 \mathrm{kN}$ load cell) at a fixed displacement rate of $0.2 \mathrm{~mm}$ $\min ^{-1}$. The strain was calculated according to the longitudinal deformation ratio recorded by a non-contacting video extensometer. For evaluating the Young's modulus and ultimate tensile strength of the composites, three samples at each CNTs- $\mu \mathrm{Al}_{2} \mathrm{O}_{3}$ hybrid fraction were tested under the same condition.

\section{Results and discussion}

3.1 Urchin-like CNTs- $\mu \mathrm{Al}_{2} \mathrm{O}_{3}$ hybrid structures
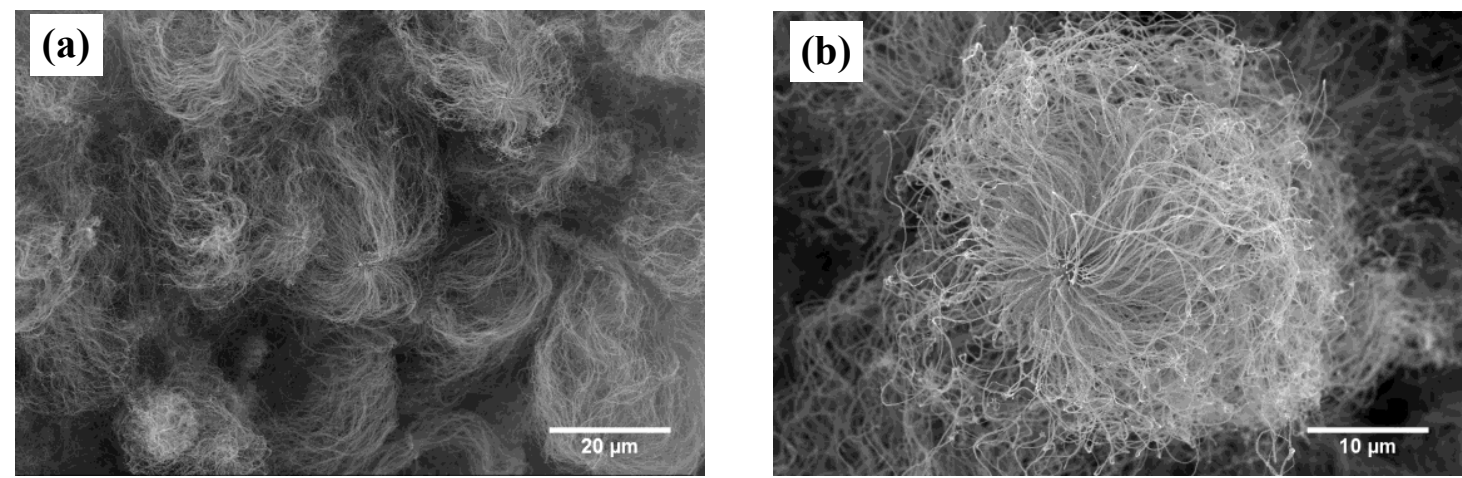

Figure 1. SEM images of the urchin-like hybrid structures consisting of multi-walled carbon nanotubes and alumina microspheres: (a) low and (b) high magnification.

In general, CNTs have huge surface area to volume ratios and aspect ratios, and are considered therefore as one kind of the ideal fillers to create polymer multifunctionalities. MWCNTs synthesized by CVD are commonly grown on surface of a plate (e.g. quartz) and formed a carpet-like layer with a thickness from several to 
hundreds of micrometers. Most of MWCNTs are aligned perpendicularly on the plate surface, but there are still a large number of entangled nanotubes which greatly hinder their homogeneous dispersion in polymer matrix, and thus restrict the composite properties and their large-scale applications. In contrast, nowadays micrometer particles or fibers have been industrially used as polymer fillers due to their good dispersion properties and cost-efficiency. A combination between microparticles and CNTs could improve CNTs' dispersion in polymer and generate high performance multifunctional composites by a cost-efficient way.

In this study, MWCNTs were produced by a floating CVD method using commercially available alumina microparticles of several micrometers in diameter as substrates. It was noticed that the growth of CNTs followed a bottom-up growth model. Under the experimental condition used, ferrocene and xylene can be efficiently decomposed by releasing active iron atoms and carbon clusters which keep high catalytic activity of iron nanoparticles and highly efficient carbon feeding for CNT growth on $\mu \mathrm{Al}_{2} \mathrm{O}_{3}$, respectively. According to microscopy analysis, the synthesized MWCNTs had an average diameter around $50 \mathrm{~nm}$ and an average length about $40 \mu \mathrm{m}$, corresponding to a growth rate about $2.5 \mu \mathrm{m} \mathrm{min}{ }^{-1}$.

The synthesized nanotubes are almost individually distributed on $\mu \mathrm{Al}_{2} \mathrm{O}_{3}$ surface. The surrounded rigid nanotubes and microspherical alumina core form an urchin-like hybrid structure as shown in Fig. 1. Meanwhile, the vacant $\mu \mathrm{Al}_{2} \mathrm{O}_{3}$ surface was also covered by a very thin carbon layer which was deposited during CVD process and also made $\mu \mathrm{Al}_{2} \mathrm{O}_{3}$ as conductive that was seen in SEM observation. 


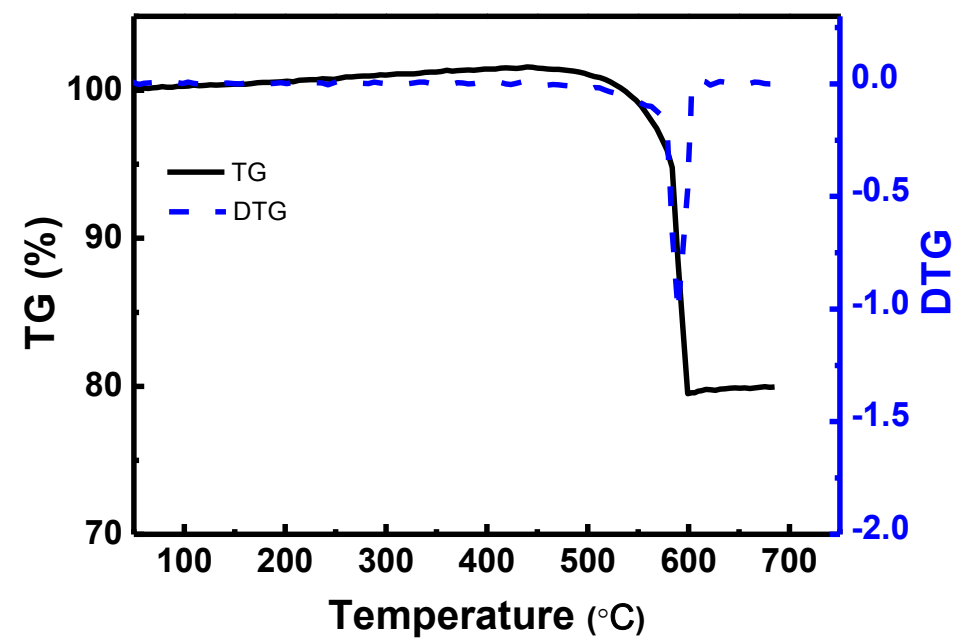

Figure 2. TG and DTG curves of the as-produced urchin-like $\mathrm{CNTs} / \mathrm{Al}_{2} \mathrm{O}_{3}$ hybrids.

The MWCNTs in urchin-like hybrids have also good thermal stability. Figure 2 shows the thermogravimetric (TG) curve and derivative thermogravimetric (DTG) curve of the CNTs- $\mu \mathrm{Al}_{2} \mathrm{O}_{3}$ hybrids obtained by thermogravimetric analysis. It can be found that the nanotubes were thermally stable up to $500{ }^{\circ} \mathrm{C}$ under oxygen and nitrogen atmosphere, and the weight loss occurred between 500 and $600{ }^{\circ} \mathrm{C}$ due to CNT oxidization. The maximum decomposition temperature was observed at $590{ }^{\circ} \mathrm{C}$ (as indicated by DTG curve) under the condition used. The residual mass above 600 ${ }^{\circ} \mathrm{C}$ corresponds to the one of alumina microparticles. Therefore, it can be deduced that the CNTs weight ratio in the as-synthesized urchin-like hybrids was about $20 \mathrm{wt} \%$ according to the measured TG curve.

\subsection{Urchin-like CNTs- $\mu \mathrm{Al}_{2} \mathrm{O}_{3}$ hybrids reinforced composites}

The as-synthesized urchin-like $\mathrm{CNTs}-\mu \mathrm{Al}_{2} \mathrm{O}_{3}$ hybrids consist of ceramic alumina microparticles and surrounded high rigid CNTs. Meanwhile, the vacant $\mu \mathrm{Al}_{2} \mathrm{O}_{3}$ surface was covered by a very thin carbon layer during CVD process which made 
$\mu \mathrm{Al}_{2} \mathrm{O}_{3}$ conductive as seen in SEM observation. This kind of hybrids is expected to have good multifunctional reinforcement effects when they are added as fillers into polymer to produce nano/micro composites. In this study, widely-used thermosetting epoxy resin was chosen as polymer matrix to demonstrate the multifunctional reinforcing roles of the urchin-like hybrids.

The nano/macro composites prepared are shown in Table 1. At each concentration $w t_{\mathrm{CNTs}-\mu \mathrm{Al} 2 \mathrm{O} 3}$, the CNTs- $\mu \mathrm{Al}_{2} \mathrm{O}_{3}$ hybrid dispersion state was examined with an optical microscope every 5 min. Take the dispersion of $w t_{\mathrm{CNTs}-\mu \mathrm{Al} 2 \mathrm{O} 3}=2.5 \% \mathrm{CNTs}-\mu \mathrm{Al}_{2} \mathrm{O}_{3}$ hybrids in epoxy resin for an example. The optical microscopy images (shown in Fig.3) demonstrate that the urchin-like hybrids can be easily dispersed in epoxy resin. And a homogeneous distribution could be found within 5 minutes' dispersion for low concentration hybrids even though the roller gap used was as large as $50 \mu \mathrm{m}$. In order to having the same dispersal procedure for all the composites with different hybrid concentrations, twenty-minute dispersion time was used in this study. Indeed, with the increase of the hybrid mass fraction, the resin viscosity increases greatly, especially at 10 wt. $\%$.

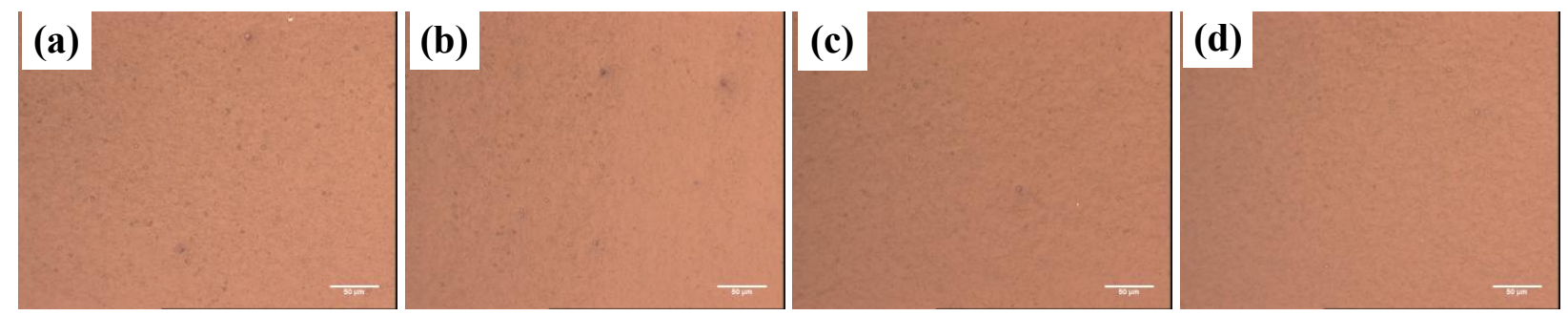

Figure 3. Evolution of dispersion state of the 0.5 wt. \% urchin-like CNTs- $\mu \mathrm{Al} 2 \mathrm{O} 3$ hybrids in epoxy resin with the increasing of the dispersion time: (a) $5 \mathrm{~min}$, (b) $10 \mathrm{~min}$, (c) $15 \mathrm{~min}$ and (d) $20 \mathrm{~min}$. 

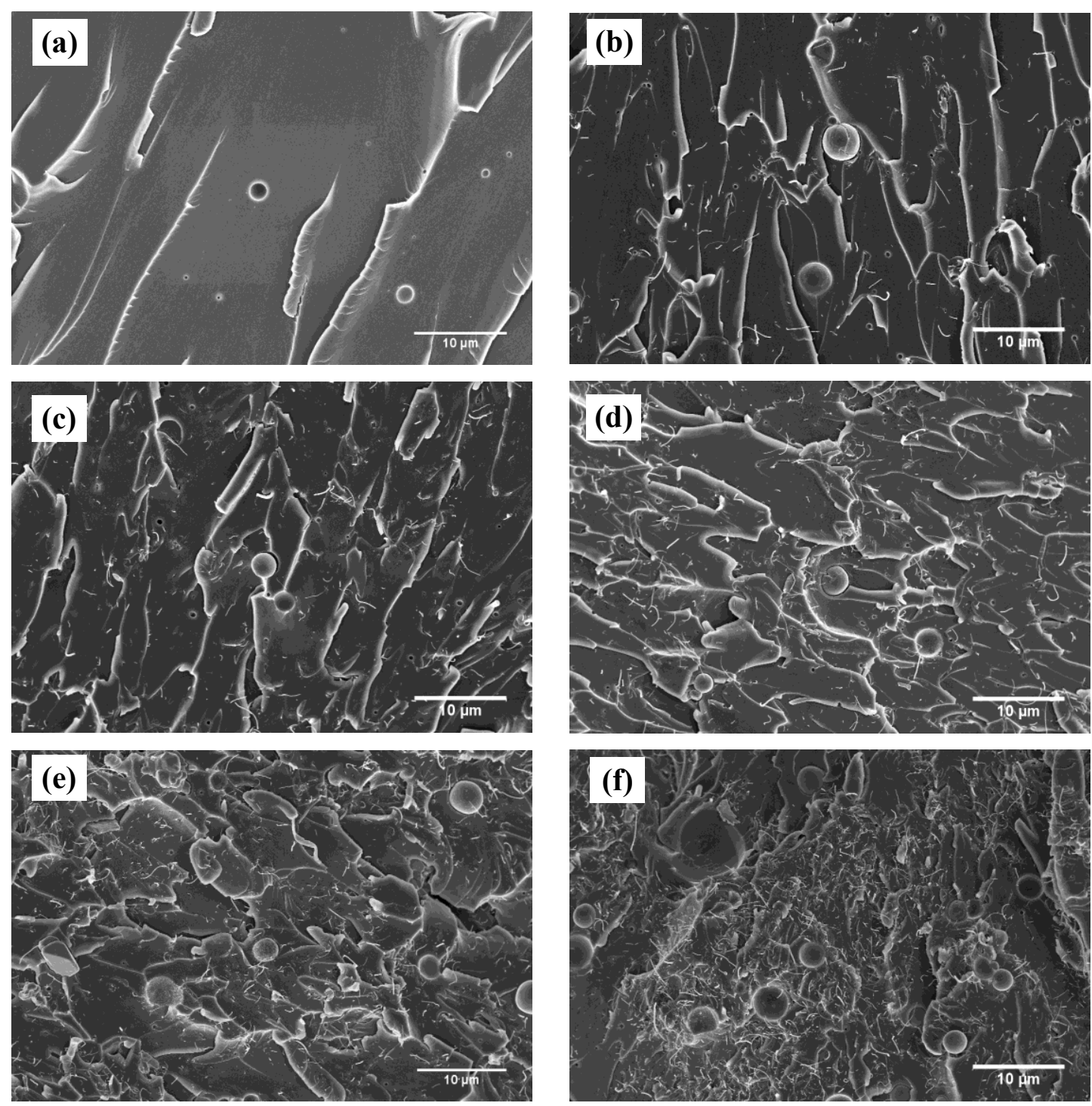

Figure 4. SEM images of the cross-section of pure epoxy (a) and of the composites with varied mass fractions of the hybrids: (b) $0.5 \%$, (c) $1.5 \%$, (d) $2.5 \%$, (e) $5 \%$ and (f) $10 \%$.

Figure 4 shows SEM images of the cross sections of the composites with varied fractions of the hybrids. No agglomeration of hybrid particles is found, and CNTs are well dispersed in the epoxy matrix. Meanwhile, it can be seen that CNTs are around $\mu \mathrm{Al}_{2} \mathrm{O}_{3}$ zone, and some of them attach on the alumina surface, and others have 
detached. Obviously, the increased number of CNTs ends emerges from the matrix with the increase of the hybrid concentration in the composite.

\subsection{Electrical conductivity and dielectric properties of the hybrid composites}

The room temperature dielectric permittivity $\left(\varepsilon^{\prime}\right)$, loss tangent $(\tan \delta)$ and $\mathrm{AC}$ conductivity of the urchin-like hybrid reinforced composites from $10^{2}$ to $10^{7} \mathrm{~Hz}$ are shown in Fig. 5. First, we can find both $\varepsilon$ ' and $\tan \delta$ of epoxy show a clear frequency dependence. But at higher frequency $\left(10^{6} \mathrm{~Hz}\right)$, there is a small plateau in $\tan \delta$ curve which is caused by the releasing of polymer segment orientation. The dielectric properties of the composites with different $w t_{\mathrm{CNTs}-\mu \mathrm{Al2O} 3}$ show strong frequency and weight fraction dependence especially at low frequency range $\left(10^{2}-10^{4} \mathrm{~Hz}\right)$. There is a dramatic increase happening in both $\varepsilon^{\prime}$ and $\tan \delta$ when the fraction $w t_{\mathrm{CNTs}}$ is close to 1 $\%$. This can be explained by classical percolation theory.[36, 37] In our system, when CNTs weight fraction is low (less than 1\%), epoxy layers isolate the conductive CNTs and the network of micro-capacitors fails to form, which makes $\varepsilon$ ' at the low level. However, when $w t_{\mathrm{CNTs}}$ approaches to the critical value (percolation threshold), each micro-capacitor will be correlated with the significant increase in the intensity of the local electric field. This usually generates surface plasma resonance or charge injection at the CNT-epoxy matrix interfaces which promotes the migration and accumulation of the charge carriers and consequently cause the interfacial polarization. It is because the interfacial polarization makes the $\varepsilon$ ' increase sharply at 
the low frequency. We use the linear fit of AC conductivity to get the percolation threshold for the composites by the power law:

$$
\sigma_{\mathrm{c}} \propto \sigma_{\mathrm{f}}\left(f_{\mathrm{c}}-f\right)^{-\mathrm{s}}
$$

where $\sigma_{\mathrm{c}}$ and $\sigma_{\mathrm{f}}$ are the conductivities of composites and conductive fillers; $f$ and $f_{\mathrm{c}}$ are the volume fraction of the fillers and percolation threshold for the system, respectively; $\mathrm{s}$ is the dimensionality-dependent critical exponent.

The result of linear fitting for the composites is shown in Fig. 5d and we find that the best linear fit gives $s=1.25$ which agrees with the universal one (in the range from 0.7 to 1.3 ). [36] The percolation threshold $f_{\mathrm{c}}$ is $0.76 \%$, corresponding $w t_{\mathrm{CNTs}}=1.3 \%$, calculated by CNT's volume fraction according to the experimental data. Compared with common CNT reinforced epoxy composites, $f_{\mathrm{c}}$ in our system is really small. The perhaps reason for this low percolation threshold is attributed to the special structure of urchin-like hybrids which improve the homogeneous dispersion of CNTs in epoxy matrix, avoiding CNT's agglomeration. Besides, this structure may also conversely prevent the restacking of $\mu \mathrm{Al}_{2} \mathrm{O}_{3}$ particles and create more area of interfaces in the composites and thus enhance the synergistic effect of $\mu \mathrm{Al}_{2} \mathrm{O}_{3}$ and epoxy. It is beneficial for better taking advantage of the original high dielectric properties of $\mu \mathrm{Al}_{2} \mathrm{O}_{3}$ which also favors to reduce $f_{\mathrm{c}}$ in the composites. Hence, this urchin-like structure of hybrids is favorable to achieve extremely low CNT's percolation threshold in the composites.

After fitting and explaining the percolation phenomenon of the composites, it is easy to understand the plateau in $\tan \delta$ curve at $100 \mathrm{~Hz}$ of the composite with 1 wt. $\%$ 
CNTs. As the CNT's fraction of $1 \%$ is approaching to $f_{c}$, more charges accumulate at interface and arouse stronger polarization. Thus the response plateau in $\tan \delta$ will appear at $100 \mathrm{~Hz}$. While for the composites with lower CNT's fractions, the polarization needs longer time and then the response plateaus will appear at much lower frequency. In addition, the value of $\varepsilon^{\prime}$ and $\tan \delta$ for 2 wt. $\%$ composite is much higher than others which also provides the evidence for the percolating behaviour since when the volume fraction is over $f_{\mathrm{c}}$, both $\tan \delta$ and $\varepsilon^{\prime}$ are extremely high due to the formation of CNT percolation network in the composites.

The frequency dependence of AC conductivity in Fig. 5c is also provided evidence for the evolution for CNT's network. It is could be found that the AC conductivity of the composite increases both with the $w t_{\mathrm{CNTs}-\mu \mathrm{Al} 2 \mathrm{O} 3}$ and the frequency when the hybrid's content at a low level. Meanwhile, the effect of CNTs- $\mu \mathrm{Al}_{2} \mathrm{O}_{3}$ reinforcement on the composite conductivity becomes less evident with the increase of the frequency. However, a huge improvement is seen when the $w t_{\mathrm{CNTs}-\mu \mathrm{Al} 2 \mathrm{O} 3}$ is beyond 2.5 wt $\%$. When $w t_{\mathrm{CNTs}-\mu \mathrm{Al} 2 \mathrm{O} 3}$ is $10 \%$, the composite conductivity becomes frequency independent and shows a conductive behaviour. This indicates that the CNT conductive network is gradually constructed when the hybrid mass fraction is beyond 2.5 wt. $\%$. 
(a)

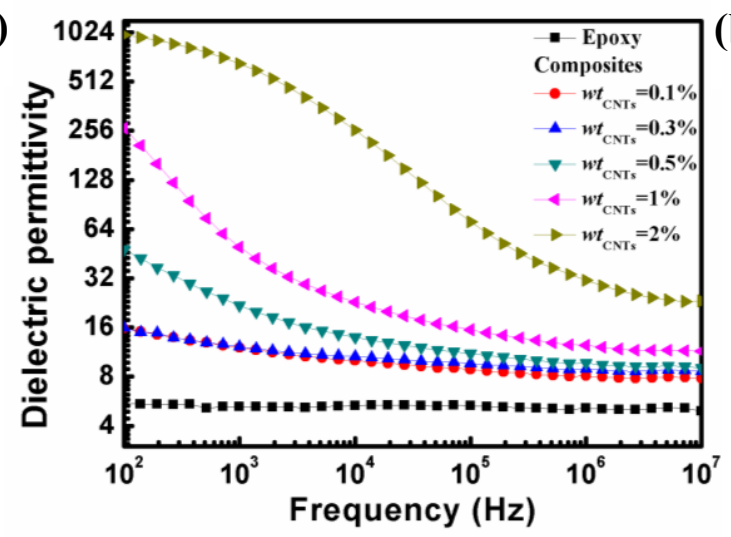

(c)

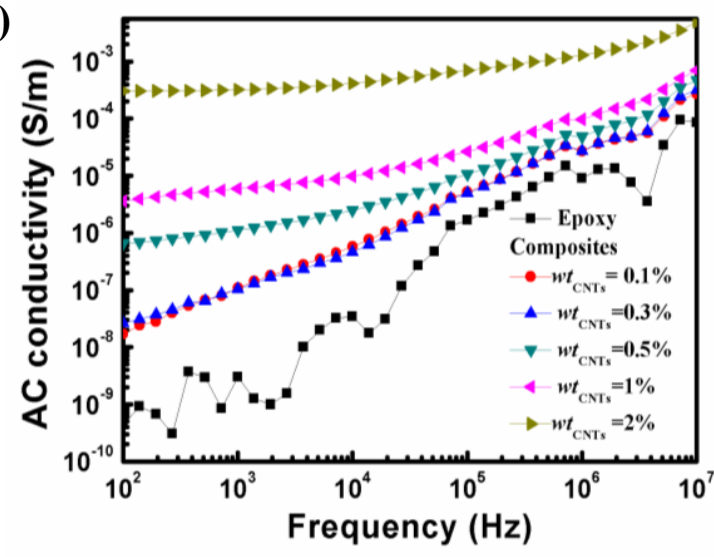

(b)

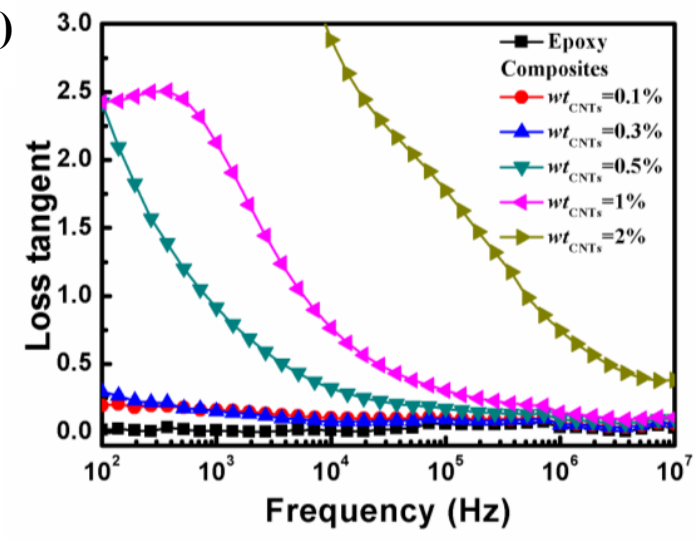

(d)

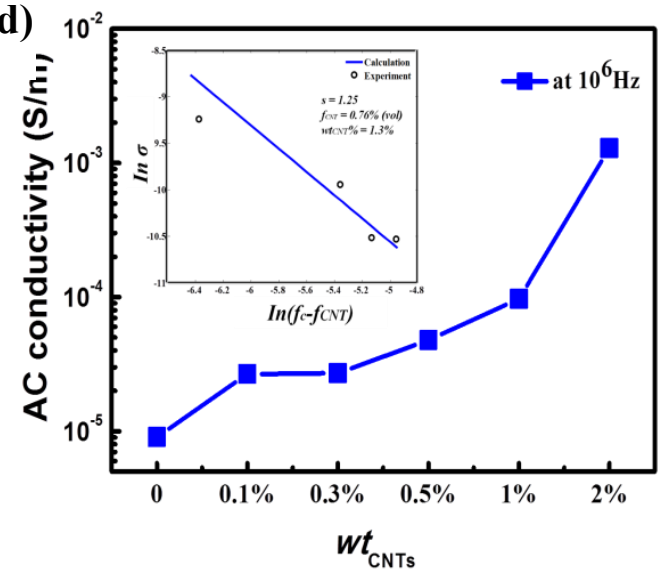

Figure 5. Frequency dependence of the dielectric properties of the composites with viared $w t_{\mathrm{CNTs}}$ from $10^{2}$ to $10^{7} \mathrm{~Hz}$ : (a) dielectric permittivity, (b) loss tangent and (c) AC conductivity. (d) the AC conductivity at $10^{6} \mathrm{~Hz}$ and the inset graph is the best liner fitting according to percolation threshold theory.

\subsection{Thermal conductivity}

Both CNTs and alumina are two excellent thermal conducting fillers to epoxy based composites, due to their outstanding thermal conductivity as high as $3000 \mathrm{Wm}^{-1} \mathrm{~K}^{-1}$ in theory for $\mathrm{CNTs}[38,39]$ and $\sim 20 \mathrm{Wm}^{-1} \mathrm{~K}^{-1}$ for alumina[40]. Therefore, the incorporation of the urchin-like CNTs- $\mu \mathrm{Al}_{2} \mathrm{O}_{3}$ hybrids in polymer matrix is expected to obtain a great improvement of the composite thermal conductivity by forming a 
ternary phase composite microstructure. The thermal conduction property of the urchin-like CNTs- $\mu \mathrm{Al}_{2} \mathrm{O}_{3}$ hybrid reinforced composites was investigated at room temperature by a Nanoflash method. First, the addition of $\mathrm{CNTs}-\mu \mathrm{Al}_{2} \mathrm{O}_{3}$ hybrids generates a quasi linear increase of the thermal diffusivity of the composites with $w t_{\mathrm{CNTS}-\mu \mathrm{Al2} 203}$, as shown in Fig $6 \mathrm{a}$. The measured $\alpha$ of pure epoxy is low, about 0.147 $\mathrm{mm}^{2} \mathrm{~s}^{-1}$, due to their irregular molecular chain arrangement after curing. An increase of near $25 \%$ of the hybrid composite $\alpha$ is achieved when $w t_{\mathrm{CNTS}-\mu \mathrm{Al} 2 \mathrm{O} 3}$ was $0.5 \%$ corresponding to $w t_{\mathrm{CNTs}}=0.1 \%$. The improvement became more evident when $w t_{\mathrm{CNTs}-\mu \mathrm{Al2O} 3}$ is above $2.5 \mathrm{wt} . \%$. The composite thermal diffusivity attains as high as 0.203 and $0.283 \mathrm{~mm}^{2} \mathrm{~s}^{-1}$ when $w t_{\mathrm{CNTs}-\mu \mathrm{Al} 2 \mathrm{O} 3}$ were $5 \%$ and $10 \%$, corresponding to an enhancement of $35 \%$ and $92 \%$, respectively. It is well known that material thermal diffusivity defines the speed of heat propagation by conduction during changes of temperature, and the high thermal diffusivity generates the fast heat propagation.
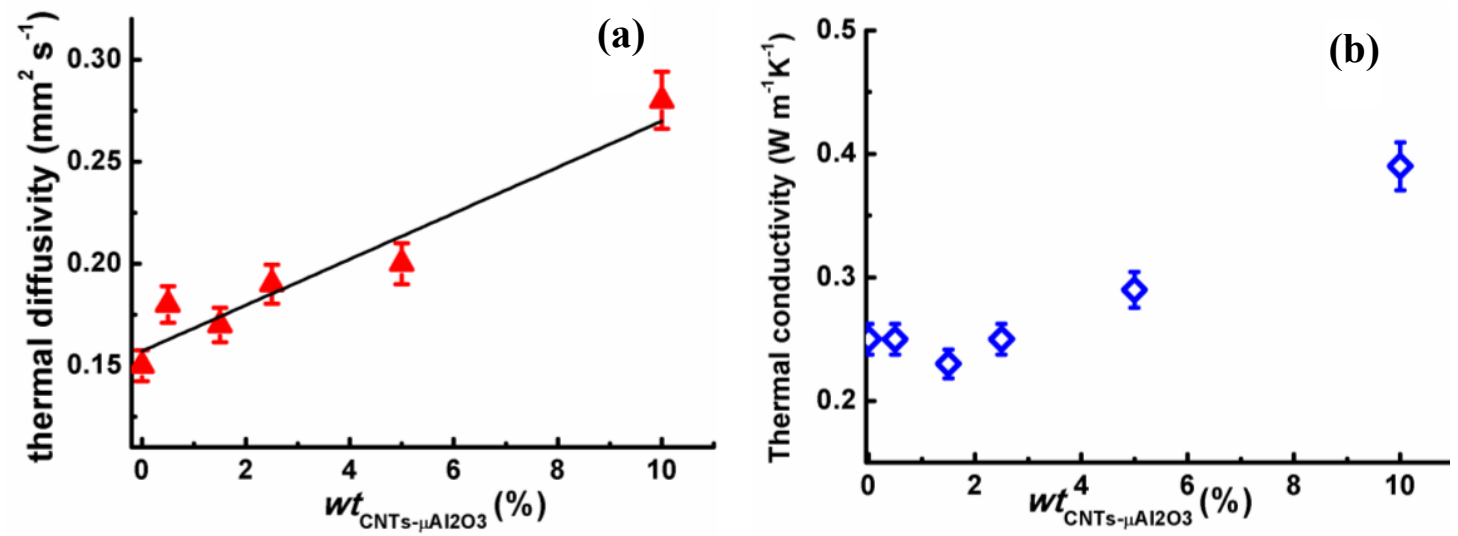

Figure 6. Evaluation of the thermal diffusivity- $\alpha$ (a) and thermal conductivity- $\lambda$ (b)of the compsoites with the mass fraction of the urchin-like CNTs- $\mu \mathrm{Al}_{2} \mathrm{O}_{3}$ hybrids. 
Second, the thermal conductivity $(\lambda)$ of the composites is associated with the composite density $(\rho)$, specific heat $\left(C_{p}\right)$ and thermal diffusivity $(\alpha)$, defined by equation $\lambda=\rho \cdot \mathrm{C}_{\mathrm{p}} \cdot \alpha$. The addition of CNTs- $\mu \mathrm{Al}_{2} \mathrm{O}_{3}$ hybrids generates the increase of composite density, mainly due to the high density of alumina $\left(\sim 3.69 \mathrm{~g} \mathrm{~cm}^{-3}\right)$, but the decrease of composite specific heat with $w t_{\mathrm{CNTs}-\mu \mathrm{Al} 2 \mathrm{O} 3}$. Therefore, the experimental results show that the composite thermal conductivity varies little when the $w t_{\mathrm{CNTS}-\mu \mathrm{Al} 2 \mathrm{O} 3}$ is below $2.5 \mathrm{wt}$. $\%$. A further increase of the hybrid fraction produces a rapid improvement of the composite thermal conductivity, due to greatly increased composite density and thermal diffusivity. The $\lambda$ reaches up to 0.29 and $0.39 \mathrm{~W} \mathrm{~K}^{-1}$ $\mathrm{m}^{-1}$ at $w t_{\mathrm{CNTs}-\mu \mathrm{Al} 2 \mathrm{O} 3} 5 \mathrm{wt} . \%\left(w t_{\mathrm{CNTs}}=1 \%\right)$ and $10 \mathrm{wt} . \%\left(w t_{\mathrm{CNTs}}=2 \%\right)$, corresponding to an increase as high as $16 \%$ and $56 \%$, respectively. As we know that thethermal conductivity of polymer composites depends significantly on the dispersion of conductive fillers. It is believed that such high improvement in thermal conductivity at relatively low filler loadings is mainly due to good dispersion of CNTs and $\mu \mathrm{Al}_{2} \mathrm{O}_{3}$ in epoxy matrix thanks to urchin-like hybrid structures.

Therefore, a high improvement of $\alpha$ and $\lambda$ of the composites is obtained by reinforcing polymer with low mass fractions of urchin-like hybrids, which is highly desired to applications in electronics where efficient heat dissipation and conduction are required.

\subsection{Mechanical properties}




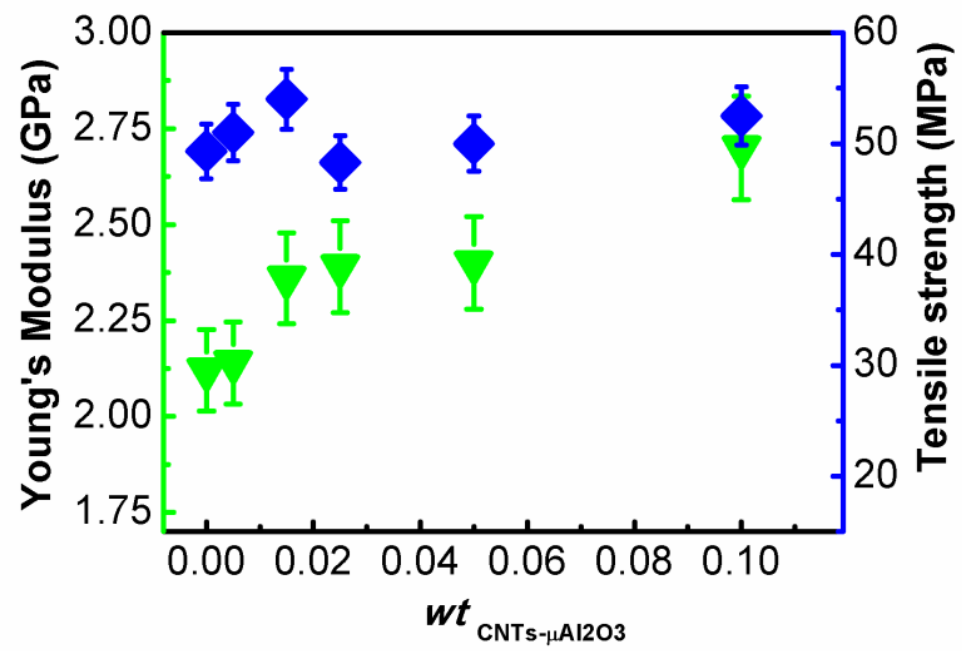

Figure 7. Young's modulus (green down-pointing triangle symbol) and tensile strength (blue diamond symbol) of the epoxy composites reinforced by varied mass fractions of the urchin-like CNTs- $\mu \mathrm{Al}_{2} \mathrm{O}_{3}$ hybrids.

The tensile properties of the composites were measured in order to evaluate the influence of hybrid addition on the composite mechanical properties. The Young's modulus $\left(E_{\text {comp }}\right)$ and ultimate tensile strength of hybrid composites at varied $w t_{\mathrm{CNTS}-\mu \mathrm{Al} 2 \mathrm{O} 3}$ are given in Fig. 7. First of all, it is found that the composite Young's modulus increases with the CNTs- $\mu \mathrm{Al}_{2} \mathrm{O}_{3}$ mass fraction. The $E_{\text {comp }}$ varies from 2.14GPa to $2.7 \mathrm{GPa}$ when the $w t_{\mathrm{CNTs}-\mu \mathrm{Al} 2 \mathrm{O} 3}$ evolves from 0.005 to 0.1 . As compared to pure epoxy $(E=2.12 \mathrm{GPa})$, an improvement as high as $26 \%$ was obtained when the $w t_{\mathrm{CNTS}-\mu \mathrm{Al} 2 \mathrm{O} 3}$ was 0.1 . Second, the ultimate tensile strength was also increased with the addition of the CNTs- $\mu \mathrm{Al}_{2} \mathrm{O}_{3}$. However, its improvement was less than $10 \%$, less evident compared with the Young's modulus ones. Meanwhile, the composite elongation to fracture has been shown a slight decrease when the hybrid mass fraction 
was beyond 1.5 , about minus $13 \%$ when $w t_{\mathrm{CNTs}-\mu \mathrm{Al} 2 \mathrm{O} 3}$ equals to 0.025 and 0.05 , and minus $20 \%$ when $w t=0.1$. This is mainly due to greatly increased volumetric fraction of alumina microparticles, as well as the increased possibility of CNTs dispersion defects at high loadings. Besides the filler mechanical properties, their interfacial connection with polymer matrix is also crucial for the mechanical reinforcement of the composites, because a solid interfacial bonding ensures the efficient load transfer between matrix and the fillers. It is believed that some efficient surface treatments could still improve the composite mechanical properties.

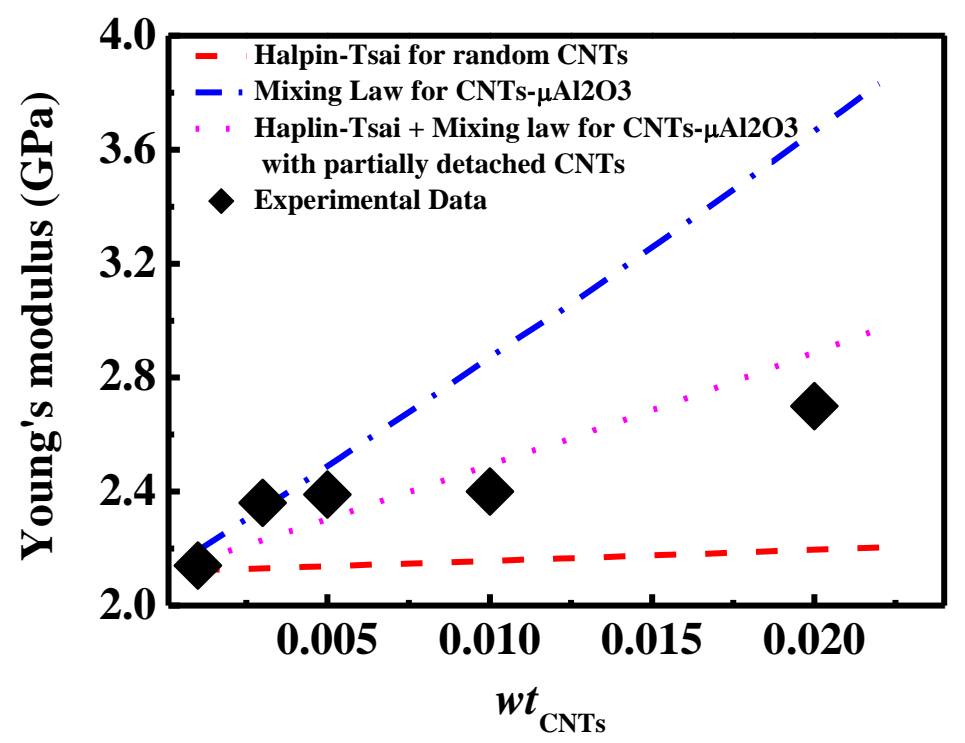

Figure 8. The calculated and experimental data of Young's modulus of the composites with different CNT weight fractions.

Furthermore, a widely used Halpin-Tsai model [41, 42] is employed in order to model the reinforcing roles of the urchin-like hybrid structures on the Young's modulus of the composites. Given the low volume fraction of alumina particles added 
in the composites, the contribution of the whole modulus is small. Thus, in the following discussion only the influence of CNTs is considered. It is well known that for randomly orientated fillers reinforced composites, the model expression is as follows:

$\mathrm{E}_{\text {comp_r }}=\mathrm{E}_{\text {Epoxy }}\left[\frac{3}{8}\left(\frac{1+(2 \mathrm{~L} / \mathrm{D}) \eta_{\mathrm{L}} \mathrm{V}_{\mathrm{f}}}{1-\eta_{\mathrm{L}} \mathrm{V}_{\mathrm{f}}}\right)+\frac{5}{8}\left(\frac{1+\eta_{\mathrm{T}} \mathrm{V}_{\mathrm{f}}}{1-\eta_{\mathrm{T}} \mathrm{V}_{\mathrm{f}}}\right)\right]$

where

$\eta_{L}=\frac{E_{f} / E_{E p o x y}-1}{E_{f} / E_{E p o x y}+2 L / D}, \eta_{T}=\frac{E_{f} / E_{E p o x y}-1}{E_{f} / E_{E p o x y}+2}, L$ and $D$ are the length and diameter of the one dimensional fillers, respectively. $\mathrm{E}_{\mathrm{Epoxy}}$ is the epoxy matrix modulus, and $\mathrm{E}_{\mathrm{f}}$ is the effective nanotube modulus.

The effective modulus of nanotubes is determined according to the following equation (3) proposed by Thostenson et al.[42]

$$
\mathrm{E}_{\mathrm{f}}=4(\mathrm{t} / \mathrm{D}) \mathrm{E}_{\mathrm{cnt}}
$$

where $\mathrm{t}$ is the nanotube outer layer thickness, $0.34 \mathrm{~nm} . \mathrm{E}_{\mathrm{cnt}}$ is the nanotube intrinsic modulus, and $450 \mathrm{GPa}$ is used in this modelling.

In the first case, we suppose that all the nanotubes are randomly and homogeneous distributed in the polymer matrix. The composite Young's modulus calculated according to equations 2 and 3 is plotted as a dashed red line shown in Fig. 8. Obviously, the calculated modulus $\mathrm{E}$ is much lower than the experimental data, when $w t_{\mathrm{CNTS}}$ is above 0.003 . And the discrepancy becomes more evident at higher $w t_{\mathrm{CNTs}}$. This means that the nanotube random distribution supposition generates an underestimated composite modulus. 
In the second case, we suppose that all the nanotubes are homogenously aligned on the alumina particle surface in an urchin-like way, as shown previously. This means that the hybrid structures were well kept in epoxy after dispersion and curing processes, and each hybrid structure could be seen as a three dimensional integrity, taking a reinforcing role in the composite. The effective modulus of one CNTs- $\mu \mathrm{Al}_{2} \mathrm{O}_{3}$ hybrid could be estimated according to the nanotube intrinsic modulus and the ratio of the equivalent nanotubes $\mathrm{N}_{\|}$in loading direction. The $\mathrm{N}_{\|}$could be calculated by summing all the loading direction projections of every nanotube homogeneously distributed on spherical alumina surface. Thus, the effective hybrid modulus $E_{\text {Hybrid }}$ could be obtained by $\mathrm{E}_{\mathrm{Hyrbid}}=\mathrm{E}_{\mathrm{cnt}} * \mathrm{~N}_{\|} / \mathrm{N}_{\mathrm{cnt}}, \mathrm{N}_{\mathrm{cnt}}$ is the average nanotube number on each alumina sphere. Then, according to a mixing law, the modulus of the composite with integrated CNTs- $\mu \mathrm{Al}_{2} \mathrm{O}_{3}$ hybrids could be described by the following equation 4:

$$
\mathrm{E}_{\text {comp_H }}=\mathrm{E}_{\text {epoxy }} * f_{\text {epoxy }}+\mathrm{E}_{\text {Hybrid }} * f_{\text {Hybrid }}
$$

The plotted curve is as the dash-dotted blue line shown in Fig. 8. It can be seen that the calculated $\mathrm{E}_{\text {comp_H }}$ matches very well with the experimental data at $w t_{\mathrm{CNTs}}=0.001$ and 0.003. An increasing overestimated modulus has been generated at higher CNTs concentrations.

In the third case, we make a more realistic supposition, that is, there are certain CNTs are detached from the alumina particles during the mechanical blending process. Indeed, the observation from optical microscopy and SEM showed that some detachment of CNTs took place during preparation procedure, and the destruction of 
the urchin-like state became much graver at higher hybrid loading levels. Then, the composite modulus is calculated by taking into account of both the detached nanotubes and the ones staying in the hybrid structure. The detached nanotubes are supposed to be homogenously distributed in polymer, and the ones in hybrid are well organised as-synthesized state in polymer. Thus, the composite modulus in this case could be obtained by combining the contributions from the above mentioned two parts CNTs, that is, hybrid contribution modeled by Halpin-Tsai equation and random CNTs contribution calculated by mixing law. The modeled modulus curve of a composite with $50 \%$ CNTs detached from hybrid structure is shown by a dotted pink line in Fig. 8. It is obvious that the modeled results correspond with the experimental data much better than the ones obtained by using the integral hybrid structure or the wholly random distribution state. That explains that the alignment of CNTs due to urchin-like hybrid is more efficient in reinforcing polymer composites than random distribution. Moreover, the composite with urchin-like hybrid fillers is isotropic both in mechanical and functional properties, unlike the anisotropic ones with aligned CNTs.

The previous results have demonstrated that the urchin-like CNTs- $\mu \mathrm{Al}_{2} \mathrm{O}_{3}$ are excellent multifunctional hybrids which greatly improve the epoxy-based composite electrical and thermal conductivity, dielectric permittivity, as well as Young's modulus and ultimate strength, at low CNT loading levels. As it was mentioned previously, the as-synthesized CNTs- $\mu \mathrm{Al}_{2} \mathrm{O}_{3}$ hybrids were mixed into epoxy resin without any further chemical treatments and surface modification. Therefore, this 
demonstrated high multifunctional improvement is mainly due to the high crystalline CNTs and their specific organization on alumina microspheres. Indeed, unlike commonly used carpets with entangled CNTs, or powders with too short CNTs, herein most CNTs are well dispersed in the matrix without obvious agglomerates, which can be verified by optical images and SEM ones of fractured sections of the composites. One of the obvious advantages of the use of hybrids with an urchin-like structure is that it can let CNTs with a regular array before being incorporated into polymer instead of an initial bundles or agglomerates. In other words, CNTs in our case are experienced two step dispersions. The first one is done by in-situ growing homogeneously on the $\mathrm{Al}_{2} \mathrm{O}_{3}$ in a separated way during CVD process; and the second one was conducted by mechanically dispersing into the polymer matrix during the mixing process. A schematic figure is provided in Fig. 9 so as to vividly describe the function of hybrids' special structure for effective dispersion of CNT in the epoxy matrix. Thus, by the application of hybrid's special structure, CNT can be effectively dispersed in the epoxy matrix.

Therefore, the urchin-like hybrids show excellent mechanically and multifunctionally reinforcing effect in epoxy polymer, showing superior overall performance than random nanotubes. Moreover, CVD is a versatile process which can be used to in-situ grow CNTs on various micron ceramic substrates, and thus to develop various hybrid structures. The process is easily scaled-up to meet large-scale application demand for producing composites in an industrial way. Thus, the 
urchin-like hybrids and their reinforced multifunctional composites exhibit a huge application potential in electronics, aeronautics and aerospace, automobile, etc.

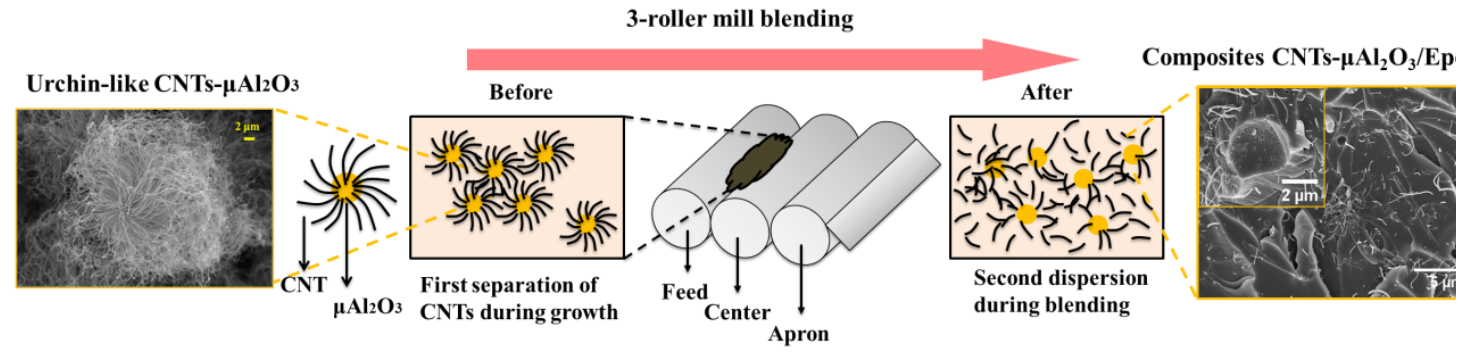

Figure 9. Schematic of urchin-like hybrid CNTs dispersion in epoxy, involving in-situ growth and mechanical mixing, which promotes an improved distribution of CNTs and $\mu \mathrm{Al}_{2} \mathrm{O}_{3}$ in the epoxy composites obtained.

\section{Conclusions}

In summary, one kind of well-organized urchin-like CNTs- $\mu \mathrm{Al}_{2} \mathrm{O}_{3}$ hybrids was in-situ synthesized by CVD using xylene and ferrocene as carbon source and catalyst precursor, respectively. And the epoxy composites reinforced by as-synthesized hybrids were produced, and their multifunctional properties were characterized. The detailed experimental results and analyses demonstrate that the urchin-like CNTs- $\mu \mathrm{Al}_{2} \mathrm{O}_{3}$ hybrids are excellent multifunctional reinforcements in epoxy polymer matrix. The dielectric permittivity and tangent loss of the CNTs- $\mu \mathrm{Al}_{2} \mathrm{O}_{3}$ /epoxy composites are frequency $\& w t_{\mathrm{CNTs}-\mu \mathrm{Al} 2 \mathrm{O} 3}$-dependent, decreasing significantly at low frequency from $10^{2}$ to $10^{4} \mathrm{~Hz}$ and increasing with $w t_{\mathrm{CNTs}-\mu \mathrm{Al} 2 \mathrm{O} 3}$ varying from 0 to 0.1 , respectively. The composite electrical conductivity was also found increased when 
$w t_{\mathrm{CNTs}}$ was above $0.3 \%$, and combing with a linear fitting according to percolation theory. The measured AC conductivity of the composites with 2 wt. \% CNTs was 3e-4 S m$~^{-1}$ at $100 \mathrm{~Hz}$. The composite thermal diffusivity showed a linear increase

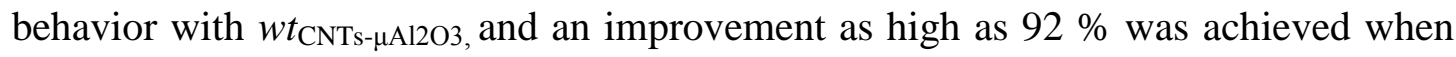
$w t_{\mathrm{CNTS}-\mu \mathrm{Al} 2 \mathrm{O} 3}=0.1$, compared with the one of pure epoxy. The composite thermal conductivity begun to increase when $w t_{\mathrm{CNTs}-\mu \mathrm{Al} 2 \mathrm{O} 3}$ is more than $2.5 \%$, and the $\lambda$ reaches up to $0.39 \mathrm{~W} \mathrm{~K}^{-1} \mathrm{~m}^{-1}$ at $10 \mathrm{wt}$. $\%\left(w t_{\mathrm{CNTs}}=2 \%\right)$, corresponding to an increase as high as $56 \%$. Moreover, the Young's modulus increased from 2.14 GPa to 2.7 GPa when the $w t_{\mathrm{CNTs}-\mu \mathrm{Al} 2 \mathrm{O} 3}$ evolves from 0.005 to 0.1 , and the highest improvement measured was $26 \%$ when the $w t_{\mathrm{CNTs}-\mu \mathrm{Al} 2 \mathrm{O} 3}$ was 0.1 , compared to pure epoxy $(E=2.12$ GPa). Meanwhile the ultimate tensile strength of the composites was slightly increased, less than $10 \%$, under the conditions studied. The multifunctional properties of the CNTs- $\mu \mathrm{Al}_{2} \mathrm{O}_{3}$ /epoxy composites was mainly due to an improved distribution of CNTs and $\mu \mathrm{Al}_{2} \mathrm{O}_{3}$ in epoxy composites, thanks to the use of an urchin-like CNTs- $\mu \mathrm{Al}_{2} \mathrm{O}_{3}$ hybrid structures. The outstanding multifunctional properties, along with easily scaled-up CVD production of the hybrids make the $\mathrm{CNTs}-\mu \mathrm{Al}_{2} \mathrm{O}_{3}$ /polymer composites promising to be widely applied in various fields from electronics to aeronautics and aerospace.

\section{ACKNOWLEDGMENT}

M. Yang acknowledges the financial support of China Scholarship Council for his PhD studies. The authors thank a lot Mrs F. Garnier for SEM characterization and Miss X. Bai and Miss X. Xiao for modeling discussion. 


\section{REFERENCES}

[1] Soutis C. Fibre reinforced composites in aircraft construction. Prog. Aeosp. Sci. 2005;41(2):143-51.

[2] Thomassin JM, Jerome C, Pardoen T, Bailly C, Huynen I, Detrembleur C. Polymer/carbon based composites as electromagnetic interference (EMI) shielding materials. Mater.Sci.Eng.R Rep. 2013;74(7):211-32.

[3] Spitalsky Z, Tasis D, Papagelis K, Galiotis C. Carbon nanotube-polymer composites: Chemistry, processing, mechanical and electrical properties. Prog. Polym. Sci. 2010;35(3):357-401.

[4] De Volder MFL, Tawfick SH, Baughman RH, Hart AJ. Carbon Nanotubes: Present and Future Commercial Applications. Science. 2013;339(6119):535-9.

[5] Paul DR, Robeson LM. Polymer nanotechnology: Nanocomposites. Polymer 2008;49(15):3187-204.

[6] Deng H, Lin L, Ji MZ, Zhang SM, Yang MB, Fu Q. Progress on the morphological control of conductive network in conductive polymer composites and the use as electroactive multifunctional materials. Prog. Polym. Sci. 2014; 39(4): $627-55$

[7] Balazs AC, Emrick T, Russell TP. Nanoparticle polymer composites: Where two small worlds meet. Science 2006;314(5802):1107-10.

[8] Balasubramanian K, Burghard M. Chemically functionalized carbon nanotubes. Small 2005;1(2):180-92.

[9] Moniruzzaman M, Winey KI. Polymer nanocomposites containing carbon 
nanotubes. Macromolecules. 2006;39(16):5194-205.

[10]Tasis D, Tagmatarchis N, Bianco A, Prato M. Chemistry of carbon nanotubes. Chem. Rev. 2006;106(3):1105-36.

[11]Shirafuji T, Noguchi Y, Yamamoto T, Hieda J, Saito N, Takai O, et al. Functionalization of Multiwalled Carbon Nanotubes by Solution Plasma Processing in Ammonia Aqueous Solution and Preparation of Composite Material with Polyamide 6. Jpn. J. Appl. Phys. 2013;52(12): 125101-6.

[12]Fujigaya T, Nakashima N. Non-covalent polymer wrapping of carbon nanotubes and the role of wrapped polymers as functional dispersants. Sci. Technol. Adv. Mater. 2015;16(2):1-21.

[13] Kar GP, Biswas S, Bose S. Simultaneous enhancement in mechanical strength, electrical conductivity, and electromagnetic shielding properties in PVDF-ABS blends containing PMMA wrapped multiwall carbon nanotubes. Phys. Chem. Chem. Phys. 2015;17(22):14856-65.

[14] Mohamed A, Anas AK, Abu Bakar S, Ardyani T, Zin WMW, Ibrahim S, et al. Enhanced dispersion of multiwall carbon nanotubes in natural rubber latex nanocomposites by surfactants bearing phenyl groups. J. Colloid Interface Sci. 2015;455:179-87.

[15]Fu SY, Feng XQ, Lauke B, Mai YW. Effects of particle size, particle/matrix interface adhesion and particle loading on mechanical properties of particulate-polymer composites. Compos. Part. B-Eng. 2008;39(6):933-61.

[16]Morsy MS, Alsayed SH, Aqel M. Hybrid effect of carbon nanotube and 
nano-clay on physico-mechanical properties of cement mortar. Constr. Build. Mater. 2011;25(1):145-9.

[17]Liu L, Grunlan JC. Clay assisted dispersion of carbon nanotubes in conductive epoxy nanocomposites. Adv. Funct. Mater. 2007;17(14):2343-8.

[18] Ma HY, Tong LF, Xu ZB, Fang ZP. Synergistic effect of carbon nanotube and clay for improving the flame retardancy of ABS resin. Nanotechnology 2007; 18(37): $375602-8$.

[19]Hwang SH, Park HW, Park YB, Um MK, Byun JH, Kwon S. Electromechanical strain sensing using polycarbonate-impregnated carbon nanotube-graphene nanoplatelet hybrid composite sheets. Compos. Sci. Technol. 2013;89:1-9.

[20] Li W, Dichiara A, Bai J. Carbon nanotube-graphene nanoplatelet hybrids as high-performance multifunctional reinforcements in epoxy composites. Compos. Sci. Technol. 2013;74:221-7.

[21]Lu HB, Yao YT, Huang WM, Leng JS, Hui D. Significantly improving infrared light-induced shape recovery behavior of shape memory polymeric nanocomposite via a synergistic effect of carbon nanotube and boron nitride. Compos. Part. B-Eng. 2014;62:256-61.

[22] Dang ZM, Yao SH, Yuan JK, Bai JB. Tailored Dielectric Properties based on Microstructure Change in BaTiO3-Carbon Nanotube/Polyvinylidene Fluoride Three-Phase Nanocomposites. J. Phys. Chem. C. 2010;114(31):13204-9.

[23]Lee G-W, Park M, Kim J, Lee JI, Yoon HG. Enhanced thermal conductivity of polymer composites filled with hybrid filler. COMPOS. PART. A-APPL. S. 2006; 
37(5): 727-34.

[24]Li H, Zhao Q, Li B, Kang J, Yu Z, Li Y, et al. Fabrication and properties of carbon nanotube-reinforced hydroxyapatite composites by a double in situ synthesis process. Carbon 2016;101:159-67.

[25]Jianli K, Philip N, Jiajun L, Chunsheng S, Naiqin Z. Achieving highly dispersed nanofibres at high loading in carbon nanofibre-metal composites. Nanotechnology. 2009;20(23): 235607-1-7.

[26]Ci LJ, Bai JB. Novel micro/nanoscale hybrid reinforcement: Multiwalled carbon nanotubes on SiC particles. Adv. Mater. 2004;16(22):2021-4.

[27]Thostenson ET, Li C, Chou T-W. Nanocomposites in context. Compos. Sci. Technol. 2005;65(3-4):491-516.

[28]He D, Bozlar M, Genestoux M, Bai J. Diameter- and length-dependent self-organizations of multi-walled carbon nanotubes on spherical alumina microparticles. Carbon. 2010;48(4):1159-70.

[29] He D, Li H, Li W, Haghi-Ashtiani P, Lejay P, Bai J. Growth of carbon nanotubes in six orthogonal directions on spherical alumina microparticles. Carbon. 2011;49(7):2273-86.

[30] He D, Li H, Bai J. Experimental and numerical investigation of the position-dependent growth of carbon nanotube-alumina microparticle hybrid structures in a horizontal CVD reactor. Carbon. 2011;49(15):5359-72.

[31]Li W, Yuan J, Lin Y, Yao S, Ren Z, Wang H, et al. The controlled formation of hybrid structures of multi-walled carbon nanotubes on $\mathrm{SiC}$ plate-like particles and 
their synergetic effect as a filler in poly(vinylidene fluoride) based composites. Carbon. 2013;51:355-64.

[32]Fan B, Bedoui F, Weigand S, Bai J. Conductive Network and $\beta$ Polymorph Content Evolution Caused by Thermal Treatment in Carbon Nanotubes-BaTiO3 Hybrids Reinforced Polyvinylidene Fluoride Composites. J. PHYS. CHEM. C 2016;120(17):9511-9.

[33]Bozlar M, He DL, Bai JB, Chalopin Y, Mingo N, Volz S. Carbon Nanotube Microarchitectures for Enhanced Thermal Conduction at Ultra low Mass Fraction in Polymer Composites. Adv. Mater. 2010;22(14):1654-8.

[34]He D, Bai J. Acetylene-Enhanced Growth of Carbon Nanotubes on Ceramic Microparticles for Multi-Scale Hybrid Structures. Chem. Vap. Deposition 2011; 17(4-6):98-106.

[35] Yamamoto N, Hart AJ, Garcia EJ, Wicks SS, Duong HM, Slocum AH, et al. High-yield growth and morphology control of aligned carbon nanotubes on ceramic fibers for multifunctional enhancement of structural composites. Carbon. 2009;47(3):551-60.

[36]Nan CW, Shen Y, Ma J. Physical Properties of Composites Near Percolation. In: Clarke DR, Ruhle M, Zok F, editors. Annual Review of Materials Research, Vol 40. Annual Review of Materials Research. 40. Palo Alto: Annual Reviews; 2010. p. $131-51$

[37]Dang ZM, Yuan JK, Yao SH, Liao RJ. Flexible Nanodielectric Materials with High Permittivity for Power Energy Storage. Adv. Mater. 2013;25(44):6334-65. 
[38]Wang M, Chen HY, Xing YJ, Wei HX, Li Q, Chen MH, et al. Enhancing Thermal Conductive Performance of Vertically Aligned Carbon Nanotube Array Composite by Pre-Annealing Treatment. J. Nanosci. Nanotechnol. 2015;15(4):3212-7. [39] Kim P, Shi L, Majumdar A, McEuen PL. Thermal transport measurements of individual multiwalled nanotubes. Phys. Rev. Lett. 2001;87(21):4.

[40]Kumari L, Zhang T, Du GH, Li WZ, Wang QW, Datye A, et al. Thermal properties of CNT-Alumina nanocomposites. Compos. Sci. Technol. 2008; 68(9): 2178-83.

[41]Coleman JN, Khan U, Blau WJ, Gun'ko YK. Small but strong: A review of the mechanical properties of carbon nanotube-polymer composites. Carbon. 2006;44(9):1624-52.

[42]Erik TT, Tsu-Wei C. On the elastic properties of carbon nanotube-based composites: modelling and characterization. J. Phys. D Appl. Phys. 2003;36(5):573. 